\title{
The Effect of L1 on Learning New L2 Vocabulary among Intermediate Proficiency Level Students
}

\author{
Maryam Pakzadian \\ Department of English, University of Isfahan, Isfahan, Iran \\ Email: maryam.pakzadian2011@gmail.com
}

\begin{abstract}
During the last decades, the role of mother tongue in language teaching has been the subject of a host of research studies ;however, quite rarely have researchers addressed such issues as comparing the use of mother tongue and other teaching techniques like paraphrasing and translation effects on students' reading comprehension ability and their ability in learning new English vocabulary. This study aimed to explore whether paraphrases vs. translations of new words in general English passages make any significant difference in intermediate proficiency level learners of English new vocabulary learning. It also aims to examine whether paraphrases or translations of texts at intermediate proficiency level affect significantly students' level of reading comprehension. The data for this study were collected through one proficiency test, 3 comprehension tests and one vocabulary test from 60 English students who study at SADR Private Language School in Isfahan. The data were analyzed descriptively and also inferentially. The overall findings of the study indicated that there was no significant difference between the comprehension of those who received Persian translation of new vocabulary and those who dealt with the paraphrase of the same new words and those who did not receive any $\mathrm{L} 1$ translation or paraphrase. The results for vocabulary test showed those who received the mother tongue definitions in front of each new word in the passage did perform significantly better on the vocabulary test than the other two groups. However study would help teachers and teacher trainers to construct and implement L1 and paraphrase in English classes more effectively.
\end{abstract}

Index Terms - L1 (here assumed as mother tongue or language that a child adopts by birth), learning L2 vocabulary, intermediate

\section{INTRODUCTION}

It is claimed by some that in any language the single biggest component is its vocabulary source. It is present every where in the language and without it any kind of attempt to convey a logical message will fail. Even in second language we can not deny its important role; it is known to both learners and instructors of English that how important vocabulary is. Without words to convey a wide range of meanings, communication is not possible in any meaningful way, no matter how successfully you mastered other areas of language. Before 1970 , vocabulary was considered to be marginal and structure received primary attention (Carter,Maccarthy,1988).however after 1910 vocabulary received a primary attention .today, the question is how to teach vocabulary and not whether it is important or not. A number of ways have been suggested to teach new words:

1) Dictionary use

2) Keyword method

3) Semantic method

4) Translation method

5) Word list method

6) The use of cognates

7) Learning vocabulary through context

A number of studies support learning words in context through guessing and there have been a number of ideas and studies in support of learning vocabulary through context, there also have been a number of studies against it.

Mondrina and Wit-Deboer (1991) investigated the influence of contextual factors on guess ability and retention of words, their findings indicated that factors that were conducive to guessing were not conducive to retention. They hypothesized that if context makes meaning very clear, retention level is actually lowered when there is a strong association of context and meaning (p.262).

Jenkins, Stein and Wysocki (1984) pointed out that learning from context is still a default explanation (p.769).

The studies mentioned above and the ones which are going to be mentioned in the review of literature have supported either learning vocabulary from context or learning it out of context. Here in this study an attempt was made to keep the context but to expose the students directly to the meaning (Persian and English) of some new words. 


\section{REVIEW OF LITERATURE}

In applied linguistics and in every other fields of study, one wishes to come across a variety of books and articles covering all areas of that particular field .Although many studies carried out in the area of vocabulary but most of them partially ignored the determining role of it and investigated this area as part of their studies, and unfortunately didn't cast light on this domain specifically. Since our concern here is vocabulary in reading, the role of vocabulary in conversations and other areas are put aside and the focus will be on vocabulary.

Vocabulary learning in a non-native language presents a different picture. To begin with, the learners are equipped with an L1 and have passed the stage of learning where they match the form and meaning of a word. Furthermore, they have learned from their L1 experience how the world works and hence they are unlikely to retrace their L1 learning route and apply it to foreign language (FL) learning.

An interesting question then follows: in what manner is an individual's lexical forms mapped onto their respective meanings when one more language is added? In other words, how or where are an L2 learner's two languages connected? (Vygotsky 1986)

$\mathrm{Na}$ and Nation (1985) studied the factors that could affect guessing vocabulary in context; they replaced low frequency words at two different densities in a context by nonsense words. The subjects were 59 teachers of English as a second language attending a diploma course with proficiency in English. They were asked to guess the meanings of nonsense words by using context were easier to guess them in higher destiny in text; verbs are easier to guess than nouns, which were easier than adverbs and adjectives. He has argued that FL learning does not repeat the course of native language acquisition but instead employs the native language as a mediator. The FL learners use the semantics of the native language as a foundation and only translate the word meanings that are already well-developed in the native language.

It appears that the mother tongue exerts a great influence over the way a foreign language is learned (Corder 1994; Swan 1997).

Ames (1966) investigated the rate of success in guessing words from context. Ames doctoral level students successfully guessed $60 \%$ of unknown words. Their subjects with vocabulary glosses, half of which were explained in English and the other half were translated into their L1 equivalents. Meanwhile, the subjects were assigned to four different teaching modes - (a) isolation, i.e., word lists, (b) minimal context, i.e., in one meaningful sentence, (c) textcontext, and (d) elaborated text-context, i.e., original text with clarifying phrases and sentences - in order to have the outcome of their memorization of new words examined. The results showed that learners had better retention of these FL words when their L1 equivalents

Stenberg and Powell (1983) distinguished between clues to the meaning of an unknown word in context and variables that facilitated or hindered the use of these clues. Were provided, irrespective of the mode in which the words had been learned.

Experienced FL learners appear to prefer L1 glosses to picture aids in learning new vocabulary.

Lotto and De Groot (1998) recruited Dutch undergraduates who had years of experience in FL learning to compare two teaching methods - word-association and picture-association. The results from two recall tests indicated that the presentation of L1-L2 word pairs during learning provided a better opportunity for acquiring L2 words than did the presentation of picture-L2 pairs.

Van Hell and Candia Mahn (1997) suggest that experienced learners, through their increasing experience in FL learning, prefer to associate the new vocabulary with the corresponding L1 words to achieve the most efficiency.

Coady et al. (1993) proposed that it was very likely that FL learners, in the case of English vocabulary learning, attached an English label to an already existing native-language schema rather than building an entirely new schema for frequently occurring universal concepts.

MacWhinney (2005), in the unified competition model, states that the L2 is parasitic on the L1 in terms of lexical learning because of the extensive amount of transfer from the L1 to the L2. In the initial stages of learning the

L2 system, learners do not formulate a separate conceptual structure but rely on L1 forms to access L2 lexical meanings.

Nag, Herman and Anderson (1985) argue that the failure of Jenkins et als study to show substantial learning from context results from the experiments failure to consider truly the nature of learning from context. As a result of their research they estimated the probabilities of learning a word from context after just one exposure to be between $10 \%$ and $15 \%$.

Duiganam (1990) investigated the effectiveness of various types of context in facilitating the teaching of word meanings. He submitted 27 nouns to three treatments word in isolation, words in sentences from dictionaries and words in paragraphs from newspapers. The subjects were to translate, produce sentences using the English target words. The result was that the sentences using the English target words. The result was that the sentences from dictionary were superior to that of words in lists and words in paragraphs from newspaper.

In another experiment conducted with Finnish learners of English,( Pickering,1982) examined findings reported in Seibert(1930) that learning foreign language words in context was interior to learning word in pairs with native language translation of the items concerned. 
The same general conclusion was reached by Cohen and Aphek (1980), in their work on the role of mnemonic association in foreign language word learning with reference to Hebrew and English.

They concluded that the recall of words in context in positively related to the proficiency level of the subjects. Perhaps the most realistic approach is to recognize that learning occurs along a continuum and that a mixture of approaches should be adopted. The results indicate the importance of the native language, to which learners attach the target language labels when attending to new words.

\section{A. Questions}

1- Is there any significant difference in comprehension when we provide mother tongue or target definitions within a context?

2- Is there any significant difference in vocabulary learning when the definitions are given in a context either in the mother tongue or in the target language?

\section{B. Hypotheses}

1- There are no significant differences in comprehension when we provide mother tongue or target definitions within the context.

2- There are no significant differences in vocabulary learning when the definitions are given in a context either in the mother tongue or in the target language.

\section{METHOD}

\section{A. Introduction}

Although there are some theories which advocate the acquisition of words in context, there have been also discrepant research findings which take the different stand. The purpose of this study is to see if providing definitions whether in mother tongue or target language in context will result in facilitating learning new words in context(in passages) or not?

To attain above goal, we choose six passages and 3 groups of learners. We provide the definitions of new words in English for one group; in second group we provide mother tongue definitions (Persian) on new words. (These definitions succeeded the words immediately in brackets). And in third group no definition will be provided. We compare the results of three groups in order to find which group will do better in learning of new words. We use two one-way ANOVAs and we make to null hypotheses as follows:

1: there are no significant differences among the three groups in comprehending the texts.

2: there are no significant differences among the three groups in learning the new words from the context.

\section{B. Subjects}

We choose 60 subjects, they are all female students, and they are all in the same level of study (intermediate level), in an English institute, SADR English language center, 2010. They are all between 14 to 20 years old. Their mother tongues are all the same (Persian) and they don't know other languages. The institute assigned them in to this level by giving them a placement test. We separate them in to 3 different classes, in each group we have 20 students, and we make sure they don't meet each other after class.

\section{Materials}

We use following materials:

1) A proficiency test consisting of three parts, namely, grammar, vocabulary and a reading comprehension section. We have this test in multiple format.

2) Three reading comprehension tests (for three groups), each consisting of six passages .each passage has multiple choice items. We choose 30- item test. Passages are all the same except for the definitions of the new words in them. In one test we give the definitions of new word in English in parenthesis immediately following each new word, in another test we provide these definitions in Persian and in the last test we have no definitions at all. The directions in tests will be given in Persian so that we make sure all the students will understand them perfectly.

3) A vocabulary test consisting of 50 items and it is a matching-type in format.

\section{Procedure}

First we make a pilot study; we give a test of 10 passages to these 60 subjects which were selected between the age 15-20 in the same level and same institute, SADR language center 2010.and we ask them to circle the words they didn't know. Then we choose the words which were difficult for more than 80 percentages of the students. And we put these words in 6 passages, and in order to make sure that the six passages have only these new words as an element of difficulty, we give these six passages to our pilot group and we ask them if there are other new words or structures that they don't understand. And if there are such words or structures we simplify them and we give same passages again to the subjects in order to assure that they understand everything in passages except those predetermined new words. Knowing that this goal was achieved, in next step we give these 3 passages to 3 classes (82subjects between 15-20), studying in the same level in SADR language center, 2010). The subjects were a proficiency test whether they were at 
the same level of proficiency or not? And we can use one-way ANOVA in this step after calculation of mean to assure that there is no significant difference between these three groups and they are all homogeneous.

TABLE1.

ANOVA FOR PROFICIENCY LEVEL OF THE THREE GROUPS

\begin{tabular}{|l|l|l|l|l|}
\hline Source of variance & S.S & d.f & M.S & F \\
\hline Between groups & 5.48 & 2 & 2.74 & 0.10 \\
\hline Within groups P<.05 & 2094.22 & 19 & 26.51 & \\
\hline
\end{tabular}

After making sure that they are homogeneous and at the same level of proficiency we give the six passages with multiple-choice items at the end of each passage to our subjects in one group (27in number), in another group (25in number) we give the same passages with English definitions provided in front of each new word and in last group (30 in number) we provide these definitions in Persian. We ask all of them to answer the multiple -choice items at the end of each passage.

After an interval of one week we give all these three groups a vocabulary test which contains the same new words as passages. The test is matching-type in format. We give directions in Persian to make sure all the subjects know what to do and also we elaborate them orally (in Persian) in the class. Then we compared the performance of these three groups in next steps.

\section{FINDINGS AND DISCUSSIONS}

After administering the tests, the data were in and they were ready to be analyzed through the statistical procedures.First, the homogeneity of the three groups was asserted through an ANOVA (one- way). Then, the passages (with the alternations mentioned in the previous sections) were given to the three groups. The subjects were asked to answer the comprehension questions following the passages (30 questions). The means for those who received only the passages, those who received the English meanings and those who received the Persian definition were respectively as follows: 17.32, 16.82 and 17.82.

Then, a (one-way) ANOVA was performed to see whether the difference between the means was significant or not?

TABLE 2.

ANOVA FOR COMPREHENSION TESTS OF THE GROUPS (3 SUBJECTS WERE ABSENT)

\begin{tabular}{|l|l|l|l|l|}
\hline Source of variance & S.s & d.f & M.S & F \\
\hline Between groups & 12.35 & 2 & 6.17 & 0.30 \\
\hline Within groups P<.05 & 1476.85 & 76 & 20.23 & \\
\hline
\end{tabular}

The result of this analysis indicated that the differences among the means of the three groups were not significant.

The next step was to give the subjects a vocabulary test containing the same new words appearing in each of the six passages .One again the means for each group was calculated as follows:

The mean for these who received no definitions was 10.22, these who had the English definitions following each new word had a mean of 11.48 and those who had the Persian meanings obtained a mean score of 13.04.Once again a (oneway) ANOVA was performed. The findings of which are shown in the following table.

TABLE 3.

ANOVA FOR VOCABULARY TEST (5 SUBJECTS WERE ABSENT)

\begin{tabular}{|l|l|l|l|l|}
\hline Source of variance & s.s & d.f & M.S & F \\
\hline Between groups & 6127.01 & 2 & 3063.50 & $* 46.07$ \\
\hline Within groups P<.05* & 4322.24 & 74 & 66.50 & \\
\hline
\end{tabular}

The F-distribution for the families of 2 d.f and 74 d.f is 2.48 ; therefore, the result shows the difference is significant.

This means that those who received the mother tongue definitions in front of each new word in the passage did perform significantly better on the vocabulary test than the other two groups.

\section{DisCUSSIONS AND SUGGESTIONS FOR FURTHER RESEARCH}

It is a popular belief that second language acquisition (SLA) is influenced by the learners first language. The clearest support for this belief comes from 'foreign' accents in the second language speech of learners. When a Frenchman speaks English, his English sounds French .The learners L1 also affects the other language levels, namely, vocabulary and grammar. This is perhaps less immediately evident, but most language learners and teachers would testify to it .It is also a popular belief that the role of the L1 in SLA is a negative one. That is, the L1 gets in the way or interferes with learning of L2 (Ellis 1986).

This view come from a learning theory called behaviorism. According to behaviorist learning theory, learning is achieved through habit formation and old habits get in the way of learning new habits. Bright and McGregor (1970) 
mention "the grammatical apparatus programmed into the mind as the first language interferes with the smooth acquisition of the second."

The behaviorist view of learning was held until 1910s and the strong version of contrastive analysis which was in fashion believed that all the errors made by L2 learners were to be traced in their mother tongues.

Dulay and Burt $(1973,1974 a)$ set out to examine this issue. In their studies, they found out that only 3 percent of all the learners' errors were result of interference.

Dulay and Burt found that, in addition to interference errors, there are first language developmental errors, those that do not reflect native language structure but are found in first language acquisition data. There are also ambiguous errors, those that cannot be categorized as either interference like or developmental and unique errors, those that do not reflect first language structure and also are not found in first language acquisition data.

Corder (1992) changes the concept 'interference' to 'intercession'. While interference is a feature of learning, intercession is considered to be as a strategy to communicate. The role of mother tongue here changes from that of 'inhibition' to that of 'facilitation'.

Krashen (1981a), also reports this. He suggests that learners can use their L1 to initiate utterances when they do not have sufficient acquired knowledge of the target language. Both Coder and Krashen believe that learners overcome their limitations in L2 by using their L1.

Perhaps a more realistic view of the role of L1 is cited by Ellis (1986). He suggests that the learners' L1 is an important determinant of SLA. It is not the only determinant, however and may not be the most important .But it is theoretically unsound to attempt a precise specification of its contribution or even to try to compare its contribution with that of other factors. The L1 is a resource of knowledge which learners will use both consciously and subconsciously to help them shift the L2 data in the input and to perform as best as they can in the L2.

The present study shows that providing learners with their mother tongue definitions, when learning English helps them a great deal in their vocabulary. The results of this study show that the mother tongue has a facilitative role. The mother tongue is likely to help students to have a clearer picture of the new words and as a result may raise their relation. Although the result of this research showed that mother tongue played an important role in acquiring new words, we should not jump right up to a certain conclusion.First, all the subjects in this research were from the same cultural and educational background and they were all Persian speakers. It is interesting to find out whether the same results would be obtained if there were subjects from different nationalities and with different mother tongues.

Second, would the same results would be obtained when students with different proficiency levels take part in the experiment? In other words, is there any difference between beginners, intermidiate and advanced subjects? Third, what is the role of sex? Do female students perform better than the male subjects? Forth, what is the role of test format? The items in the research were multiple choices and matching type would the same results be achieved if we changed the test formats? Fifth, does the kind of text involved (e.g, narrative, descriptive, procedural, etc) play a role? Sixth, does the kind of vocabulary involved (e.g, concrete and abstract) play a role?

Obviously, it is definitely not possible to arrive at a finalized conclusion unless all these and perhaps other questions (for example, the Density ,the ratio of unknown words to known words ) are answered .this ,of course ,calls for more studies and research to be carried on in the future.

\section{REFERENCES}

[1] Adams, M.J., and Collins, A.(1979).A schemata-theoretic view or reading. New directions in Discourse Processing, R.D. Freedle(Ed.),1-22.Norwood,N.J.:Ablex

[2] Anderson, c., and Alvarez, G.(1979).The development of strategies for assignment of semantic information to unknown lexemes in text. Lenguas Para Objectivos Especificos 5:2-13.

[3] Ames,W.s.(1966). The development of a classification schemata of contextual aids. Reading Research Quarterly. 2(1):57-82.

[4] Beck, I., Mckeown, M, and Omanson, R.(1987).The effects and uses of diverse vocabulary instructional techniques. The Nature of Vocabulary Acqusition, M.Mckeown and M.Curtis(Eds.), 147-163.Hillsdale,N.J:Lawrence Erlbaum Associates.

[5] Bloomfield, C. (1933). language. London: Allen\&Unwin.

[6] Blum, S., and Levenston, E.A. (1978b). Universals of lexical simplification. Language learning.28(2):399-415.

[7] Bright, j., and McGregor, G. (1970).Teaching English as a Second Language: Theory and Techniques for the secondary stage. London: Longman.

[8] Brown, J.(1979).Vocabulary: Learning to be imprecise. Modern English Teacher. 7(1):25-7.

[9] Coady, J., Magoto, J., Hubbard, P., Graney, J. and Mokhtari, K., (1993). High frequency vocabulary and reading proficiency in ESL readers. In: Huckin, T., Haynes, M. and Coady, J., eds. Second language reading and vocabulary learning. Norwood, NJ: Ablex, 217-228.

[10] Cohen, A., and Aphek, E.(1980).Retention of second language vocabulary over time:Investigating the role of mnemonic associations. System. 8(3):221-35.

[11] Corder, s. (1992).A role for the mother tongue.Language Transfer in Language Learning, S.Gass and L.Selinker (Eds.), 20-30. John Benjamins publishing company: Amesterdam/Philadelphia.

[12] Duignan, M.A.M.(1990). an investigation of second language vocabulary acquisition through reading. Dissertation Abstracts International.A:51,9,March, 3044-A.

[13] Dulay, H., and Burt, M. (1973).Should we teach children syntax? Language Learning.23:245-58

[14] Dulay, H. and Burt, M. (1974b). Natural Sequence in child second language acquisition. Language Learning. 24: 37-53. 
[15] Jenkins. J. R, Stein. N. L., and Wysocki, K. (1984). Learning Vocabulary through reading. American Educational Research Journal.21 (4): 767-78.

[16] Krashen, S.(1981a).Second Language and Second Language Learning.Oxford:Pergamon.

[17] Lotto, L. and De Groot, A.M.B., (1998). Effects of learning method and word type on acquiring vocabulary in an unfamiliar language. Language Learning, 48 (1), 31-69.

[18] MacWhinney, B., (2005). New directions in the competition model. In: Tomasello, M. and Slobin, D.I., eds. Beyond naturenurture: Essays in honor of Elizabeth Bates. Mahwah, NJ: Lawrence Erlbaum, 81-110.

[19] Mondria, J, and Wit De Boer, M.(1991).The effects of contextual richness on the guessability and the retention of words in a foreign language. Applied Linguistic.12:249-267.

[20] Na and Nation, I.S.P. (1985). Factors affecting guessing vocabulary in context. RELC Journal 16, 1: 33-42.

[21] Nagy. W. E, Herman, P.A, and Anderson, R.C. (1985).Learning words from context.Reading Research Quarterly.20 (2):23353.

[22] Pickering, M.(1982).Context free and context dependent vocabulary learning. System.10(1):79-83.

[23] Sternberg, R. j., and Powell, J.S. (1983).Comrehenging verbal comprehension. American Psychology.38:878-93.

[24] Van Hell, J.G. and Candia Mahn, A. (1997). Keyword mnemonics versus rote rehearsal: learning concrete and abstract foreign words by experienced and inexperienced learners. Language Learning, 47 (3), 507-546.

[25] Vygotsky, L. (1986). Thought and language. Cambridge, MA: The MIT Press.

[26] Wilkins, D.A. (1972).Linguistic and Language Teaching. London: Edward Arnold.

[27] Yule, G. (1985).The Study of Language Cambridge: Cambridge University Press.

Maryam Pakzadian has an MA in ' Teaching English as a foreign Language' from University of Isfahan and she has got her BA in 'English Literature' from University of Isfahan. She has been involved in research in English Literature, Literary Translation, psycholinguistics, and Computer Assisted Language Learning. He has presented different lectures on Literary Translation, Teaching Translation and CALL.

Maryam is currently working on 'Persian Translation of William Blake's Songs of Innocence and Songs of Experience' and 'A New Approach to teaching Literature in Iranian Universities'. 